\title{
Eye Movement Abnormalities in Essential Tremor
}

\author{
by \\ Magdalena Wójcik-Pędziwiatrr1, Klaudia Plinta², Agnieszka Krzak-Kubica³, \\ Katarzyna Zajdel ${ }^{4}$,Marcel Falkiewicz', Jacek Dylak6, Jan Ober6, \\ Andrzej Szczudlik ${ }^{7}$ Monika Rudzińska²
}

Essential tremor (ET) is the most prevalent movement disorder, characterized mainly by an action tremor of the arms. Only a few studies published as yet have assessed oculomotor abnormalities in ET and their results are unequivocal. The aim of this study was to assess the oculomotor abnormalities in ET patients compared with the control group and to find the relationship between oculomotor abnormalities and clinical features of ET patients. We studied 50 ET patients and 42 matched by age and gender healthy controls. Saccadometer Advanced (Ober Consulting, Poland) was used to investigate reflexive, pace-induced and cued saccades and conventional electrooculography for evaluation of smooth pursuit and fixation. The severity of the tremor was assessed by the Clinical Rating Scale for Tremor. Significant differences between ET patients and controls were found for the incidence of reflexive saccades dysmetria and deficit of smooth pursuit. Reflexive saccades dysmetria was more frequent in patients in the second and third phase of ET compared to the first phase. The reflexive saccades latency increase was correlated with severity of the tremor. In conclusion, oculomotor abnormalities were significantly more common in ET patients than in healthy subjects. The most common oculomotor disturbances in ET were reflexive saccades dysmetria and slowing of smooth pursuit. The frequency of reflexive saccades dysmetria increased with progression of ET. The reflexive saccades latency increase was related to the severity of tremor.

Key words: saccades, smooth pursuit, electrooculography

\section{Introduction}

Essential tremor (ET) is a well-recognized movement disorder characterized by a symmetrical, postural and/or kinetic tremor, which involves mainly hands and forearms. Some other signs are also present in many cases of ET patients. In advanced stages, some patients reveal cerebellar signs: intension tremor, dysdiadochokinesia or tandem walking disturbances (Hubble et al., 1997; Klebe et al., 2005; Singer et al., 1994; Stolze et al., 2001). In older ET patients, mild cognitive deficits with

1 - Department of Neurology, The John Paul II Hospital, Krakow, Poland.

2 - Department of Neurology, Medical University of Silesia, Katowice, Poland.

3 - Department of Neurology, Central Clinical Hospital of Medical Academy, Katowice, Poland.

4 - Department of Otolaryngology, Jagiellonian University Medical College, Krakow, Poland.

5 - Laboratory of Psychophysiology, Nencki Institute of Experimental Biology, Polish Academy of Science, Warsaw, Poland.

6 - Institute of Biocybernotechnic and Biomedical Engineering, Polish Academy of Science, Poznan, Poland.

7 - Department of Neurology, Jagiellonian University Medical College, Krakow, Poland. 
frontal region dysfunction or dementia were also found (Bermajo-Pareja et al., 2007; Higgins et al., 2008; Lombardi et al., 2001; Louis et al., 2007). Chandran et al. (2011) reported neuropsychiatric abnormalities such as depression, anxiety and insomnia. Numerous experimental and clinical studies indicate that the cerebellum is involved in the pathophysiology of ET (Farkas et al., 2006; Louis et al., 2004; Singer et al., 1994; Willis et al., 1994).

There are many studies assessing oculomotor abnormalities in Parkinson disease (PD), Huntington disease (HD) and spinocerebellar ataxias (Leigh and Kennard, 2004). Although ET is considered to be the most prevalent movement disorder, the literature regarding the associated oculomotor abnormalities is scarce. Only three studies focused on this topic have been published so far, but the results of them are unequivocal (Gitchel et al., 2013; Helmchen et al., 2003; Trillenberg et al., 2006). Helmchen et al. (2003) reported deficits of smooth pursuit initiation and suppression of the vestibulo-ocular reflex, but no abnormalities of reflexive saccades or fixation and optokinetic nystagmus (OKN). Trillenberg et al. (2006) revealed the presence of reflexive saccades dysmetria in the eye-hand coordination task in ET. In contrast, Gitchel et al. (2013) reported the presence of prolonged latency and slowed velocity of reflexive saccades and fixation break by an increased number of square wave jerks intrusions. So far, there have been no studies evaluating volitional saccades in ET patients.

The objective of our study was to assess the oculomotor abnormalities in ET patients compared with a control group and to find a relationship between oculomotor abnormalities and clinical features (ET phase, age, disease duration, severity of tremor, cognitive disturbances and depression).

\section{Material and Methods}

The participation in the study was proposed to all patients with diagnosis of ET according to the National Institute of Health Collaborative Genetic Criteria (1996) (Chouinard et al., 1997), who visited the Movement Disorders Outpatients Clinic, Department of Neurology, University Hospital in Krakow, Poland, from January, 2009 to June, 2010. The control group was composed of subjects with negative family history and unaffected by the tremor, recruited among patients' spouses, clinic employees, acquaintances and medical students. The control group consisted of subjects matched strictly, in a case-to-case manner, by age ( \pm 3 years) and gender to ET patients. Each participant provided written

consent before the beginning of the study procedures. Exclusion criteria were: restriction of the eyes mobility, scotomy, severe refraction abnormalities, red or green color blindness, other diseases of the nervous system or muscles affecting the eyes motility, intake of drugs which affected eye movements except for levodopa, propranolol, primidone and benzodiazepines, alcohol or drug abuse, history of drug usage or exposure to carbon monoxide or other chemical agents, schizophrenia or other severe psychiatric diseases, symptomatic hypo- or hyperthyroidism, autoimmune disease, malignancy, severe cardiac, renal, hepatic or pulmonary insufficiency, past thalamotomy or deep brain stimulation and contraindication for MRI. Each patient was interviewed about the history of the tremor including the age of the onset, symptoms, response to the alcohol and disease course. Patients and controls were asked about concomitant medical history, current medication, stimulants, contact with toxic substances and family history. Each participant underwent neurological examination extended by the Mini Mental State Examination and evaluation of depression symptoms in the Beck Depression Inventory (BDI). The severity of tremor was assessed using the Clinical Rating Scale for Tremor (CRST) (Fahn et al., 1988). The phase of ET was defined according to Critchley (1972) criteria. An ophthalmologist screened each participant. The standard biochemistry panel, including thyroid hormones and a fasting glucose level, was determined for ET patients. In order to exclude Wilson's disease, also the ceruloplasmine level in blood was investigated in patients before the study. Brain MRI was performed for each ET patient to exclude other causes of the tremor and oculomotor abnormalities. Each patient underwent the levodopa challenge to exclude the diagnosis of PD.

The eye movement recording was carried out in the morning, before the participants took 
the next dose of their medication. They were also asked not to take any stimulant (i.e. alcohol or coffee) for at least $24 \mathrm{~h}$ before the examination of the eye movements. Participants were installed in a dimmed and soundproof room, in the comfortable armchair with a head support, at a fixed distance of one meter from a white screen. The examined subjects were asked to follow the visual stimulus with their eyes, which was being projected on the screen, according to the instruction given by the investigator.

A Saccadometer Advanced device (Ali et al., 2006) served for recording of reflexive and volitional saccades. The analysis of saccades was carried out by the mean of LatencyMeter software, version 4.11 (Ober Consulting, Poland). The apparatus comprises a frontal plate with four low-power lasers which project bilaterally luminous targets, the green one and the red one in the middle line and two red ones in the horizontal line, 10 degree (deg) from the central targets. The frontal plate was attached to the head of examined subject with a special elastic stripe, which prevented the interference of excessive head movements in the recordings. We examined ten-degree and twenty-degree reflexive saccades, ten-degree cued saccades and twenty-degree pace-induced saccades. Additionally, latency of reflexive saccades was assessed with the gap and overlap paradigm. In the gap paradigm, there was a 200-ms pause between disappearance of the central fixation target and appearance of the peripheral one. For the cued saccades paradigm, participants were asked to look at the peripheral target (left or right) according to the color of the central cue (red or green, respectively). One hundred experimental trials were recorded for evaluation of reflexive and cued saccades. For pace-induced saccades, participants were asked to shift alternately the gaze between continuously illuminated peripheral targets as quickly and accurately as possible for $30 \mathrm{~ms}$. All experimental trials were preceded by 20 calibration trials. Tendegree reflexive saccades were assessed for latency. Twenty-degree reflexive saccades were used for evaluation of the amplitude and velocity. In the gap and overlap paradigm, only the latency was assessed. For pace-induced saccades, we evaluated the number of saccades, latency, amplitude and velocity. In cued saccades, we evaluated the error index (incorrect saccades/number of trials) and the latency of correct saccades. An incorrect saccade meant a saccade executed in an inappropriate direction, against the cue. We assessed for each subject separately each twenty-degree reflexive saccade and pace-induced saccade for the presence of abnormal metric. Normal range of saccade amplitude was set from 17-20 deg, which considered $85-100 \%$ of distance from the initial to final fixation target (Bötzel et al., 1993; Moschner et al., 1994; Wessel et al., 1998). Then the rate of hypometric and/or hypermetric saccades was calculated. Pathological dysmetria was considered when the frequency of hypometric or hypermetric saccades was greater than $23 \%$ (Wessel et al., 1998).

Conventional electrooculography (EOG) was used to investigate smooth pursuit, optokinetic nystagmus $(\mathrm{OKN})$ and fixation. The recordings were performed by means of three electrodes: two electrodes were attached to the outer canthi of the eyes and the third one below the eye. The sinusoidal paradigm was applied to study smooth pursuit. The participants were instructed to follow a light spot with their eyes. It was projected on a white screen and moved \pm 45 deg from central fixation with frequency of 0.2 Hz. For each participant, four recordings, composed of four cycles, were performed. Smooth pursuit gain (SPG) was calculated by dividing peak eye velocity to target velocity. For further analysis, we used the arithmetical mean of four recordings. For examination of fixation, each participant was asked to gaze at a central $2 \mathrm{deg}$ target, which stayed still for $5 \mathrm{~ms}$ and then shifted to $10 \mathrm{deg}$. The smooth pursuit sinusoid and fixation recordings were assessed visually for the presence of catch-up saccades and fixation break, respectively, by two independent investigators.

The study was approved by the Jagiellonian University Bioethics Committee. All research procedures were performed in compliance with the principles included in the Declaration of Helsinki.

Statistical Analysis

The statistical analysis was carried out using commercial statistical software (STATISTICA version 9.0 for Windows 7.0, StatSoft. Inc., PL). Numerical variables were presented by means \pm standard deviation (SD). The normal distribution was verified using the 
Kolmogorov-Smirnov test. None of the numerous variables presented normal distribution. Statistical significance for quantitative variables between two groups was evaluated by the Mann-Whitney $\mathrm{U}$ test and between more than two groups by Kruskal-Wallis one-way analysis of variance. Statistical significance between categorical variables was analyzed with a $\chi 2$ test or, in case of small sample size, with the Fisher's test. The Spearman's rank correlation coefficient was used to assess correlation between numerical variables. A $p$ value $<0.05$ was considered as statistically significant.

\section{Results}

Fifty eligible patients, 24 females and 26 males, aged 18-85 years (mean age: $59.2 \pm 21.7$ years), were enrolled into the study (Table 1 ). The control group was composed of 42 healthy volunteers, 25 females and 17 males, aged 18-85 years (mean age: $60.6 \pm 19.0$ years). There were no significant differences in age and gender between ET patients and controls.

Reflexive saccades dysmetria occurred in $32(64.0 \%)$ ET patients and in $14(33.3 \%)$ controls $\left(\chi^{2}=8.59, p=0.003\right)$. Hypometric reflexive saccades were found in $21(42.0 \%)$ ET patients and in $11(26.2 \%)$ controls, hypermetric saccades in 9 $(18.0 \%)$ ET patients and in $4(9.5 \%)$ controls and co-occurrence of hypometric and hypermetric saccades in $4(8.0 \%)$ ET patients and in $1(2.4 \%)$ control subject. Figure 1 shows normal saccades of a healthy control subject. Figure 2 presents dysmetric saccades of an ET patient. There were no significant differences between the ET and control groups for other reflexive and volitional saccades variables.

The mean gain of smooth pursuit decreased significantly in ET patients compared with controls $(0.75$ vs. $0.86 ; p=0.01)$. No significant differences were found for the presence of saccadic intrusions between ET patients and controls.

We divided the ET group into three subgroups according to the phase of the disease. There were $8(16.0 \%)$ patients in the first phase, $20(40.0 \%)$ in the second phase and 22 in the third phase of ET $(44.0 \%)$. Patients in the third phase of the disease had significantly more severe ET signs assessed

by CRST than patient in the first $(p=0.001)$ and second phase $(p=0.021)$ (Table 3). The frequency of reflexive saccades dysmetria was the lowest in the first, over twofold higher in the second and the highest in the third phase of ET (25.0 vs. 65.0 vs. $77.3 \% ; p=0.019$ ). The reflexive saccades amplitude was significantly smaller in the third phase of the disease compared to the first phase (17.2 vs. $19.4 \mathrm{deg} ; p=0.020)$. We did not find any other significant differences for the other variables evaluated in the study between patients in different phases of ET (Table 2).

\begin{tabular}{|c|c|}
\hline & Table 1 \\
\hline \multicolumn{2}{|c|}{ Characteristic of ET patients } \\
\hline Male : Female & $26: 24$ \\
\hline Age of the onset: mean \pm SD (years) & $40.1 \pm 21.3$ \\
\hline Disease duration: mean \pm SD (years) & $19.4 \pm 12.4$ \\
\hline Severity of disease (CRST score): mean \pm SD & $30.9 \pm 15.0$ \\
\hline MMSE score: mean \pm SD & $28.1 \pm 1.9$ \\
\hline BDI score: mean \pm SD & $11.7 \pm 9.8$ \\
\hline The occurrence of the head tremor (\%) & $29(58 \%)$ \\
\hline $\begin{array}{l}\text { Number (\%) of patients with improvement of tremor after } \\
\text { alcohol }\end{array}$ & $18(36 \%)$ \\
\hline Number (\%) of patients with family history of tremor & $28(56 \%)$ \\
\hline Drugs having impact on the eye movements: & \\
\hline Propranolol & $31(62.0 \%)$ \\
\hline Primidone & $10(20.0 \%)$ \\
\hline Benzodiazepines (clonazepam or alprazolam) & $2(5.0 \%)$ \\
\hline $\begin{array}{c}\text { Tremor Severity Scale, CRST-Clinical Ra } \\
\text { MMSE - Minimental state Examination, BDI- }\end{array}$ & $\begin{array}{l}\text { or Tremor, } \\
\text { ssion Inventory }\end{array}$ \\
\hline
\end{tabular}


Table 2

The results of eye movement assessment in ET patients and controls

\begin{tabular}{|c|c|c|c|c|c|c|c|}
\hline \multirow[t]{3}{*}{ Parameter } & \multicolumn{4}{|c|}{ ET patients } & \multirow[b]{2}{*}{ Controls } & \multirow{2}{*}{\multicolumn{2}{|c|}{$\begin{array}{l}\text { Statistical } \\
\text { difference }(p)\end{array}$}} \\
\hline & \multirow{2}{*}{$\begin{array}{l}\text { All } \\
\text { A }\end{array}$} & \multirow{2}{*}{$\begin{array}{l}\text { Phase I } \\
\text { B }\end{array}$} & \multirow{2}{*}{$\begin{array}{l}\text { Phase } \\
\text { II } \\
\text { C }\end{array}$} & \multirow{2}{*}{$\begin{array}{l}\text { Phase III } \\
\text { D }\end{array}$} & & & \\
\hline & & & & & E & A vs. E & $\begin{array}{l}\text { B vs. C } \\
\text { vs. D }\end{array}$ \\
\hline \multicolumn{8}{|l|}{ Reflexive saccades } \\
\hline Latency (ms) & $\begin{array}{c}261.5 \pm \\
101.8\end{array}$ & $\begin{array}{c}178.4 \pm \\
35.2\end{array}$ & $\begin{array}{c}263.0 \pm \\
86.3\end{array}$ & $\begin{array}{c}293.4 \pm \\
118.2\end{array}$ & $\begin{array}{c}227.1 \pm \\
49.2\end{array}$ & NS. & NS. \\
\hline Amplitude (deg) & $\begin{array}{c}16.9 \pm \\
4.3\end{array}$ & $\begin{array}{c}18.5 \pm \\
4.1\end{array}$ & $\begin{array}{c}19.2 \pm \\
2.7\end{array}$ & $\begin{array}{c}17.6 \pm \\
4.2\end{array}$ & $\begin{array}{c}17.1 \pm \\
4.2\end{array}$ & NS. & $\begin{array}{c}\text { B vs. C } \\
0.021\end{array}$ \\
\hline Hypometria (\%) & $\begin{array}{c}21 \\
(42.0 \%)\end{array}$ & $\begin{array}{c}1 \\
(12.5 \%)\end{array}$ & $\begin{array}{c}11 \\
(38.1 \\
\%)\end{array}$ & $\begin{array}{c}9 \\
(42.9 \%)\end{array}$ & $\begin{array}{c}11 \\
(26.2 \%)\end{array}$ & NS. & NS. \\
\hline Hypermetria (\%) & $\begin{array}{c}9 \\
(18.0 \%)\end{array}$ & $\begin{array}{c}1 \\
(12.5 \%)\end{array}$ & $\begin{array}{l}1 \\
(4.8 \\
\%)\end{array}$ & $\begin{array}{c}5 \\
(22.7 \%)\end{array}$ & $\begin{array}{c}4 \\
(9.5 \%)\end{array}$ & NS. & NS. \\
\hline $\begin{array}{l}\text { Total number }(\%) \text { of patients with } \\
\text { dysmetria }\end{array}$ & $\begin{array}{c}32 \\
(64.0 \%)\end{array}$ & $\begin{array}{c}1 \\
(25.0 \%)\end{array}$ & $\begin{array}{c}13 \\
(65.0 \\
\%)\end{array}$ & $\begin{array}{c}17 \\
(77.3 \%)\end{array}$ & $\begin{array}{c}14 \\
(33.3 \%)\end{array}$ & $\begin{array}{l}\chi^{2}=8.59 \\
p=0.003\end{array}$ & $p=0.019$ \\
\hline Velocity (deg/ms) & $\begin{array}{l}492.3 \pm \\
202.0\end{array}$ & $\begin{array}{c}545.9 \pm \\
45.3\end{array}$ & $\begin{array}{c}505.8 \pm \\
68.2\end{array}$ & $\begin{array}{c}476.5 \pm \\
119,4\end{array}$ & $\begin{array}{l}484.5 \pm \\
120.7\end{array}$ & NS. & NS. \\
\hline Latency in gap paradigm (ms) & $\begin{array}{c}190.0 \pm \\
67.2\end{array}$ & $\begin{array}{c}137.5 \pm \\
28.6\end{array}$ & $\begin{array}{c}184.4 \pm \\
58.6\end{array}$ & $\begin{array}{c}215.5 \pm \\
75.4\end{array}$ & $\begin{array}{c}177.1 \pm \\
54.4\end{array}$ & NS. & NS. \\
\hline Latency in overlap paradigm (ms) & $\begin{array}{c}285.6 \pm \\
91.9\end{array}$ & $\begin{array}{c}211.4 \pm \\
25.8\end{array}$ & $\begin{array}{c}286.8 \pm \\
78.6\end{array}$ & $\begin{array}{l}3114 \pm \\
107.9\end{array}$ & $\begin{array}{c}250.5 \pm \\
56.2\end{array}$ & NS. & NS. \\
\hline \multicolumn{8}{|l|}{ Pace-induced saccades } \\
\hline Number of saccades & $\begin{array}{c}45.9 \pm \\
12.1\end{array}$ & $\begin{array}{c}55.9 \pm \\
14.9\end{array}$ & $\begin{array}{c}46.4 \pm \\
10.4\end{array}$ & $\begin{array}{c}42.6 \pm \\
11.9\end{array}$ & $\begin{array}{c}49.5 \pm \\
11.5\end{array}$ & NS. & NS. \\
\hline Latency (ms) & $\begin{array}{c}746.2 \pm \\
213.9\end{array}$ & $\begin{array}{c}542.1 \pm \\
144.8\end{array}$ & $\begin{array}{c}695.0 \pm \\
120.2\end{array}$ & $\begin{array}{c}857.0 \pm \\
231.5\end{array}$ & $\begin{array}{c}719.1 \pm \\
194.3\end{array}$ & NS. & NS. \\
\hline Amplitude (deg) & $16.9 \pm 4.3$ & $19.3 \pm 1.4$ & $\begin{array}{c}20.4 \pm \\
5.1\end{array}$ & $18.9 \pm 3.0$ & $17.1 \pm 4.2$ & NS. & NS. \\
\hline Hypometria & $\begin{array}{c}11 \\
(22.4 \%)\end{array}$ & $\begin{array}{c}3 \\
(37.5 \\
\%)\end{array}$ & $\begin{array}{c}4 \\
(20.0 \\
\%)\end{array}$ & $\begin{array}{c}4 \\
(18.2 \%)\end{array}$ & $\begin{array}{c}12 \\
(28.6 \%)\end{array}$ & NS.* & NS. \\
\hline Hypermetria & $\begin{array}{c}9 \\
(18.0 \%)\end{array}$ & $\begin{array}{c}1 \\
(12.5 \%)\end{array}$ & $\begin{array}{c}4 \\
(20.0 \\
\%)\end{array}$ & $\begin{array}{c}4 \\
(18.2 \%)\end{array}$ & $\begin{array}{c}7 \\
(17.9 \%)\end{array}$ & NS.* & NS. \\
\hline Velocity (deg/ms) & $\begin{array}{c}509.9 \pm \\
107.4\end{array}$ & $\begin{array}{c}533.6 \pm \\
67.2\end{array}$ & $\begin{array}{c}529.7 \pm \\
111.1\end{array}$ & $\begin{array}{c}486.8 \pm \\
115.0\end{array}$ & $\begin{array}{c}505.2 \pm \\
116.7\end{array}$ & NS. & NS. \\
\hline \multicolumn{8}{|l|}{ Cued saccades } \\
\hline Rate of errors (\%) & $\begin{array}{c}29.2 \pm \\
19.1\end{array}$ & $\begin{array}{l}23.3 \pm \\
22.7\end{array}$ & $\begin{array}{c}26.3 \pm \\
20.4\end{array}$ & $\begin{array}{c}35.0 \pm \\
15.7\end{array}$ & $\begin{array}{c}26.8 \pm \\
16.1\end{array}$ & NS. & NS. \\
\hline Latency (ms) & $\begin{array}{c}533.0 \pm \\
147.8\end{array}$ & $\begin{array}{c}391.9 \pm \\
64.0\end{array}$ & $\begin{array}{c}514.7 \pm \\
86.5\end{array}$ & $\begin{array}{c}585.6 \pm \\
161.8\end{array}$ & $\begin{array}{c}506.7 \pm \\
171.5\end{array}$ & NS. & NS. \\
\hline \multicolumn{8}{|l|}{ Smooth pursuit } \\
\hline SPG (\%) & $\begin{array}{c}74.6 \pm \\
12.1\end{array}$ & $\begin{array}{c}86.0 \pm \\
16.0\end{array}$ & $\begin{array}{c}77.3 \pm \\
10,5\end{array}$ & $\begin{array}{c}70.3 \pm \\
13.4\end{array}$ & $\begin{array}{c}86.0 \pm \\
2.8\end{array}$ & $p=0.010$ & NS. \\
\hline
\end{tabular}


Table 3

The comparison of demographic and clinical features of patients in different phases of ET

\begin{tabular}{|c|c|c|c|c|c|}
\hline Phase of ET & I & II & III & $\mathrm{P}$ & $\begin{array}{l}\text { Post hoc } \\
\text { analysis }\end{array}$ \\
\hline No. (\%) & $\begin{array}{c}8 \\
(16.0 \%)\end{array}$ & $\begin{array}{c}20 \\
(40.0 \%)\end{array}$ & $\begin{array}{c}22 \\
(44.0 \%)\end{array}$ & - & - \\
\hline $\begin{array}{l}\text { Mean age } \pm S D \\
\text { years }\end{array}$ & $42.9 \pm 21.9$ & $56.6 \pm 23.7$ & $58.9 \pm 20.1$ & $0,018^{1}$ & 1 vs. $3: 0.021$ \\
\hline No. $(\%)$ of males & $\begin{array}{c}6 \\
(75.0 \%)\end{array}$ & $\begin{array}{c}7 \\
(35.0 \%)\end{array}$ & $\begin{array}{c}13 \\
(59.0 \%)\end{array}$ & NS. ${ }^{2}$ & - \\
\hline $\begin{array}{l}\text { Mean age of onset } \\
\pm \text { SD years }\end{array}$ & $33.5 \pm 20.0$ & $40.3 \pm 24.0$ & $42.4 \pm 18.0$ & NS. ${ }^{1}$ & - \\
\hline $\begin{array}{l}\text { Mean disease } \\
\text { duration } \pm S D \\
\text { years }\end{array}$ & $9.4 \pm 7.9$ & $16.4 \pm 11.0$ & $25.7 \pm 11.7$ & $0.000^{1}$ & $\begin{array}{l}1 \text { vs. } 3: 0.000 \\
2 \text { vs. } 3: 0.014\end{array}$ \\
\hline $\begin{array}{l}\text { Mean score of } \\
\text { CRST } \pm S D\end{array}$ & $17.6 \pm 7.7$ & $27.2 \pm 14.2$ & $39.1 \pm 13.0$ & $0.000^{1}$ & $\begin{array}{l}1 \text { vs. } 3: 0.001 \\
2 \text { vs. 3: } 0.021\end{array}$ \\
\hline
\end{tabular}

${ }^{1}$ ANOVA Kruscal - Wallis test, $2 \chi^{2}$ Pearsona test

Table 4

Correlation between eye movements variables and age, disease duration, severity of tremor, cognitive disturbances and depression in ET patients

\begin{tabular}{|c|c|c|c|c|c|c|c|c|c|c|c|}
\hline \multirow{3}{*}{$\begin{array}{l}\text { Type of the } \\
\text { eye } \\
\text { movement } \\
\begin{array}{l}\text { Reflexive } \\
\text { saccades }\end{array}\end{array}$} & \multirow{2}{*}{$\begin{array}{c}\text { Variable } \\
\text { Latency }\end{array}$} & \multicolumn{2}{|c|}{$\begin{array}{l}\text { Age } \\
\mathrm{R}, p\end{array}$} & \multicolumn{2}{|c|}{$\begin{array}{c}\text { Disease } \\
\text { duration } \\
\quad \mathrm{R}, p\end{array}$} & \multicolumn{2}{|c|}{$\begin{array}{c}\text { Severity of } \\
\text { tremor ET } \\
\text { (CRST) } \\
\text { R, } p\end{array}$} & \multicolumn{2}{|c|}{$\begin{array}{l}\text { Severity of } \\
\text { cognitive } \\
\text { disturbances } \\
\text { (MMSE) R, } p \\
\end{array}$} & \multicolumn{2}{|c|}{$\begin{array}{c}\text { Severity of } \\
\text { depression (BDI) } \\
\text { R, } p\end{array}$} \\
\hline & & 0.610 & 0.000 & 0.366 & 0.010 & 0.386 & 0.006 & -0.418 & 0.003 & 0.079 & 0.587 \\
\hline & Amplitude & -0.040 & 0.790 & 0.055 & 0.714 & -0.072 & 0.628 & 0.116 & 0.436 & -0.171 & 0.250 \\
\hline & Velocity & -0.130 & 0.364 & 0.152 & 0.309 & -0.068 & 0.651 & 0.009 & 0.953 & -0.044 & 0.768 \\
\hline & $\begin{array}{l}\text { Latency in } \\
\text { gap } \\
\text { paradigm }\end{array}$ & 0.690 & 0.000 & 0.403 & 0.004 & 0.096 & 0.511 & -0.287 & 0.045 & 0.111 & 0.449 \\
\hline & $\begin{array}{c}\text { Latency in } \\
\text { overlap } \\
\text { paradigm }\end{array}$ & 0.480 & 0.000 & 0.357 & 0.012 & 0.141 & 0.332 & -0.236 & 0.102 & 0.075 & 0.609 \\
\hline \multirow{4}{*}{$\begin{array}{l}\text { Pace- } \\
\text { induced } \\
\text { saccades }\end{array}$} & $\begin{array}{c}\text { Number of } \\
\text { saccades }\end{array}$ & -0.300 & 0.032 & -0.375 & 0.008 & -0.237 & 0.101 & 0.247 & 0.087 & -0.077 & 0.601 \\
\hline & Latency & 0.330 & 0.019 & 0.381 & 0.007 & 0.419 & 0.003 & -0.281 & 0.051 & 0.127 & 0.384 \\
\hline & Amplitude & -0.150 & 0.280 & -0.262 & 0.069 & -0.171 & 0.239 & 0.305 & 0.033 & -0.119 & 0.414 \\
\hline & Velocity & -0.280 & 0.051 & -0.227 & 0.116 & -0.044 & 0.763 & 0.249 & 0.083 & -0.069 & 0.635 \\
\hline \multirow{2}{*}{$\begin{array}{l}\text { Cued } \\
\text { saccades }\end{array}$} & Error index & 0.150 & 0.284 & 0.199 & 0.465 & 0.186 & 0.200 & -0.262 & 0.069 & 0.142 & 0.329 \\
\hline & Latency & 0.120 & 0.394 & 0.240 & 0.097 & 0.104 & 0.478 & -0.230 & 0.111 & -0.066 & 0.650 \\
\hline $\begin{array}{l}\text { Smooth } \\
\text { pursuit }\end{array}$ & SPG & -0.050 & 0.859 & 0.199 & 0.460 & 0.242 & 0.384 & 0.096 & 0.733 & -0.112 & 0.690 \\
\hline
\end{tabular}

CRST - Clinical Rating Scale for Tremor, MMSE - Minimental State Examination, $B D I-$ Beck Depression Inventory 
Analysis of eye movement variables in relation to tremor severity and other clinical features revealed that reflexive saccades latency rose significantly with increasing age $(\mathrm{r}=0.61, p=$ $0.000)$, longer disease duration $(\mathrm{r}=0.37, p=0.010)$, an increase in the CRST score $(\mathrm{r}=0.39, p=0.006)$ and with a decrease in MMSE $(\mathrm{r}=-0.42, p=0.003)$. Latency in the gap paradigm rose significantly with increasing age $(r=0.69, p=0.000)$, longer disease duration $(\mathrm{r}=0.40, p=0.000)$ and a decrease in MMSE ( $r=-0.29, p=0.045)$. Latency in the overlap paradigm rose significantly with increasing age $(\mathrm{r}=0.48, p=0.000)$ and longer disease duration $(\mathrm{r}=0.36, p=0.012)$. The paceinduced saccades number dropped significantly with increasing age $(\mathrm{r}=-0.30, p=0.032)$ and longer disease duration $(\mathrm{r}=-0.37, p=0.008)$. Paceinduced saccades latency rose significantly with increasing age $(r=0.33, p=0.019)$ and longer disease duration $(\mathrm{r}=0.38, p=0.007)$. Pace-induced saccades amplitude dropped significantly with a decrease in the MMSE score $(\mathrm{r}=0.30, p=0.033)$. No other significant correlation was found between other eye movement measurements and clinical features including age, disease duration, severity of tremor in the CREST score, MMSE score and BDI score (Table 4).

\section{Discussion}

The study showed the presence of eye movement abnormalities including reflexive saccades dysmetria and deficits of smooth pursuit attributed to the lesion of cerebellar oculomotor areas in ET patients. The frequency of saccades dysmetria increased with progression of the disease. The reflexive saccades latency increase was related to the increase in the severity of tremor, the decrease in MMSE, increasing age and disease duration. Volitional saccades and overlap effect on reflexive saccades latency in ET were tested for the first time.

In contrast to the previous investigators (Gitchel et al., 2013; Helmchen et al., 2003; Trillenberg et al., 2006), we found the deficit of accuracy in reflexive saccades in ET patients. The frequency of reflexive saccades dysmetria in the ET group was nearly twofold higher compared to the control group (64.0\% versus $33.3 \%$ ). Moreover, ET patients in the second and third phase of the disease performed more dysmetric saccades than patients in the first phase. Since age influences the saccades accuracy (Abel et al., 1983), a high percentage of dysmetric saccades in the control group could be explained by the older age of our subjects. Helmchen et al. (2003) found reflexive saccades hypometria in $16.0 \%$ of ET patients and $20.0 \%$ of controls, but we did not find information about the percentage of hypermetric saccades in their report. We applied the same criteria of saccades dysmetria as Helmchen et al. (2003) (Bötzel et al., 1993; Moschner et al., 1994; Wessel et al., 1998), however, the frequency of corrective saccades was not calculated, as the Saccadometer Advanced device records only the first-step saccade, which is an obvious limitation of our study. Different results of previous authors (Helmchen et al., 2003, Trillenberg et al., 2006) could be explained by smaller material. Since tendegree saccades are less likely to be dysmetric, the amplitude of evaluated saccades might be substantial as well. Helmchen et al. (2003) studied 20 ten-degree and 20 twenty-degree saccades for each of 17 ET patients (240 ten-degree and 240 twenty-degree saccades) and 11 controls (220 tendegree and 220 twenty-degree saccades), whereas we studied 100 only twenty-degree reflexive saccades for each of 50 ET patients (5000 twentydegree saccades) and 42 controls (4200 saccades). Trillenberg et al. (2006) studied only single saccades in the group of 12 ET patients and 14 controls, however, they assessed the first-step saccade amplitude and they did not calculate the frequency of dysmetric saccades. In the study of Gitchel et al. (2013), the group of ET patients included 60 ET patients and 60 controls (12 000 saccades), however, the disease duration was significantly shorter then in our study $(11.3 \pm 13.7$ years versus $19.4 \pm 12.4$ years), which might have influenced the results. Saccades dysmetria is a hallmark of cerebellum lesion. The amplitude of saccades is controlled by the posterior vermis (Helmchen and Buttner, 1995; Sato and Noda, 1992) and fastigial nuclei (Fuchs et al., 1993; Helmchen et al., 1994). The unilateral lesion of posterior vermis results in hypometry of ipsilateral saccades and hypermetry of contralateral saccades (Sato and Noda, 1992). The inverse effect occurs in the lesion of fastigial nucleus of one side (Robinson et al., 1993). Experimental studies on monkeys showed that a lesion in the oculomotor vermis caused shortening of saccades, an increase in saccadic 
amplitude variability and loss of adaptive capability of saccadic amplitudes (Barash et al., 1999; Optican and Robinson, 1980; Takagi et al., 1998).

The study showed significant slowing of smooth pursuit in ET patients. So far, a smooth pursuit deficit in ET has been assessed in only one study of Helmchen et al. (2003) on 10 patients with a dominant intention tremor and 7 patients with a dominant postural tremor, in two different methods i.e. the sine wave paradigm and stepramp paradigm (Rashbass, 1961). Smooth pursuit is assessed globally in the sine wave paradigm. In the Rashbass paradigm, parts of smooth pursuit including the initial saccade, acceleration phase and maintain phase are assessed separately. It allows for distinction between a frontal dysfunction and a cerebellar dysfunction of smooth pursuit. Prolonged initial saccade latency is characteristic for the frontal dysfunction. The deficit in the acceleration and maintain phase is detected in the cerebellum dysfunction. In total, cerebellectomy abolishes smooth pursuit, it plays a crucial part in its generation. Apart from control of saccades metrics, the posterior vermis and fastigial nuclei are involved in the acceleration phase of smooth pursuit, while flocculus and paraflocculus contribute to the maintaining phase. Helmchen et al. (2003) found reduction of the acceleration and maintenance of velocity of smooth pursuit, which was more prominent in patients with an intention tremor compared to patients with a postural tremor, without evidence of the frontal dysfunction. We assessed the deficit of smooth pursuit only in the sine wave paradigm. However, prolongation of saccades latency was not found in the assessment of neither reflexive nor volitional saccades, so we can exclude a frontal dysfunction as a cause of the smooth pursuit deficit. Helmchen et al. (2003) found reduction of smooth pursuit in the sine wave paradigm in ET patients, without significant differences between groups with a dominant postural tremor and a dominant intention tremor. We did not find significant differences of the smooth pursuit deficit between groups of ET patients in different phases of ET. Helmchen et al. (2003) reported a significant correlation between variables of the step ramp and severity of tremor. In our study a significant correlation between SPG and the severity of tremor was not found. The study of Helmchen et al. (2003) does not include information whether the significant correlation occurred between SPG and the severity of tremor.

In contrary to the results of Gitchel et al. (2013) and in accordance with Helmchen et al. (2003) and Trillenberg et al. (2006), our study showed no abnormalities of dynamic variables of reflexive saccades like latency and velocity. There are numerous factors which influence the latency and velocity of saccades, including age, some medication, tiredness and conditions of the examination. We tried to eliminate all confounding factors as much as possible by following implementing the following methods. First, we selected our material carefully by exclusion of all subjects with possible other causes of the eye movement disturbances and tremor. Second, we performed our recordings in the morning and before taking medication. Third, we enrolled subjects and the control group in a caseto-case manner, matching them strictly by age $( \pm 3$ years) and gender to ET patients. Gitchel et al. (2013) confirmed that the eye movement recordings were performed while $75 \%$ of patients were taking medication (topiramat, b-blocker or primidone). They did not perform neuroimaging examination for each patient, so it was not possible to exclude the contribution of additional processes such as vascular changes in the brain. We observed a tendency for prolongation of reflexive saccades latency and a decrease of their velocity from the first to the third phase of ET, however, the differences were not statistically significant. In the study of Helmchen et al. (2003), reflexive saccades latency was slightly prolonged and its velocity was reduced in ET patients with a dominant intention tremor compared with controls, but statistical significance was not reached. Gitchel et al. (2013) noticed that their values of latency and velocity were close to the ones reported by Helmchen et al. (2003) and concluded that since the findings of dynamic variables in ET patients were subtle changes from normal, the discrepancies in the reports may account for differences in statistical power. Since age influences latency and velocity of saccades, the findings described above might have been caused by a higher number of elder subjects. Reflexive saccades latency depends mainly on cortical and subcortical areas of the saccadic system. The velocity of saccades is programmed 
by the brainstem saccades generator (Leigh and Zee, 2006).

We did not find impairment of the gap and overlap effect on reflexive saccades latency in ET. Our results of reflexive saccades latency in the gap paradigm remained in accordance with the results of Trillenberg et al. (2006). To our knowledge, there have been no reports yet which concern the influence of the overlap paradigm on the saccades latency in ET patients. The introduction of a pause between the central and peripheral fixation target shortens the latency and increases the number of express saccades, while maintenance of the central target during saccade performance causes prolongation of its latency (Leigh and Zee, 2006). The structures that are involved in these physiological processes are fixation centers localized in the frontal eye field and superior coliculus (Schiller et al., 1980). There are two causes of saccades latency shortening in the gap paradigm (Pratt et al., 2000). First, the release of fixation constitutes a signal for the oculomotor system that the expected peripheral target is going to appear. Second, the release of visual fixation turns off the superior colliculus mechanism, which keeps the eyes at rest. In the overlap paradigm, the maintenance of the initial fixation target requires the application of a stronger stimulus in order to overcome the fixation mechanism. Saccades latency in the gap and overlap paradigm is pathologically prolonged in HD (Ali et al., 2006) or Alzheimer disease (Bötzel et al., 1993). The most prominent abnormality in the overlap paradigm is fixation spasm when the subject is not able to initiate the eye movement until the central target is displayed. The results of our study showed that fixation centers of the frontal eye field and superior coliculus were spared in ET.

To the best of our knowledge, this is the first study to evaluate volitional saccades in ET patients. We investigated two types of volitional saccades, pace-induced and cued ones, however, no abnormalities were found. The assessment of volitional saccades gives some information regarding the state of cortical and subcortical areas. The lesion of the dorso-lateral prefrontal cortex increases the error rate and latency of cued saccades (Leigh et al., 2004), whereas involvement of basal ganglia i.e. in PD, causes a decrease in the number and an increase in latency of pace- induced saccades (Kennard and Lueck, 1989).

Our study did not show any disruption of fixation, the nystagmus was not noted and the frequency of saccadic intrusions was similar to the control group. Our results stayed on line with the report of Helmchen et al. (2003). Gitchel et al. (2013) found fixation highly stable in ET patients, however, it was interrupted by an increased number of square wave jerks (Gitchel et al., 2013).

Our results showed that only the reflexive saccades latency increase was related to the severity of tremor. It was related to disease duration and a decrease in the MMSE score as well. Apart from this variable, the other ones, which depend on functioning of higher levels of the brain, like latency in the gap and overlap paradigm, latency of pace-induced saccades and the pace-induced saccades number, were related to the disease duration and age. Also the reflexive saccades latency in the gap test increase and the pace-induced saccades amplitude decrease were related to the decrease in MMSE. None of abovementioned variables were abnormal, which suggests that some cortical or subcortical areas might be only slightly involved in ET. There is some evidence of mild, cognitive deficits in ET patients (Balaban et al., 2012; Kim et al., 2010; Lacritz et al., 2002; Sahin et al., 2006), particularly in attentional and executive functions (Tröster et al., 2002) probably connected with the dysfunction of fronto-subcortico-cerebellar circuits (Cerasa et al., 2009; Passamonti et al., 2011; Sahin et al., 2006). There is a need of further studies regarding volitional saccades with relation to the cognitive function in ET.

The etiopathomechanism of ET is not well known. Many reports published in last decades support the important role of cerebellum and olivo-cerebellar dysfunctions in ET pathophysiology. Deuschl and Pinto (2000) suggested that pathological oscillating activities from the inferior olivary nucleus are transmitted to the cerebellum via the olivo-cereballar pathway. Magneto- and electroencelograhic studies revealed the involvement of transcortical pathways in ET as well (Halliday et al., 2005). The presence of the intention tremor, gait disturbances and dysdiadochokinesia in an advanced stage of ET argues per se for involvement of the cerebellum in ET (Singer et al., 1994). The kinematic studies of limb movements showed also 
the presence of cerebellar abnormalities in ET (Britton et al., 1994; Deuschl et al., 2000; Koster et al., 2002; Stolze et al., 2001). Functional imaging studies (PET, fMRI) revealed hyperactivation of cerebellar hemispheres and its connections with the brainstem (Colebatch et al., 1990; Louis., 2004). Dupuis et al. (1989) reported remission of ET after the ipsilateral cerebellar stroke. Suppression of ET after ablation or deep brain stimulation performed on the thalamic ventralis intermedius nucleus, which receives neuronal input from the cerebellum, is another argument for the cerebellum role in pathogenesis of ET. MRI spectroscopy (Pagan et al., 2003) and

\section{Acknowledgements}

This study was supported by the grant no. NN402271336 from the Polish Ministry of Science.

Some results of this study have been already presented on a poster session at the $20^{\text {th }}$ International Congress of the International Parkinson and Movement Disorder Society in Berlin, June 19-23, 2016.

\section{References}

Ali FR, Michell AW, Barker RA, Carpenter RHS. The use of quantitative oculomerty in the assessment of Huntington`s disease. Exp Brain Res, 2006; 169: 237 - 245

Barash S, Melikyan A, Sivakov A, Zhang M, Glickstein M, Thier P. Saccadic dysmetria and adaptation after lesions of the cerebellar cortex. J Neurosci, 1999; 19: 10931-10939

Bermejo-Pareja F, Louis ED, Benito-Leon J. Risk of incident dementia in essential tremor: a population-based study. Mov Disord, 2007; 22: 1573 - 1580

Bötzel K, Rottach K, Büttner U. Normal and pathological saccadic dysmetria. Brain, 1993; 116: $337-353$

Britton TC, Thompson PD, Day BL, Rothwell JC, Findley LJ, Marsden CD. Rapid wrist movements in patients with essential tremor. The critical role of the second agonist burst. Brain, 1994; 117: 39-47

Cerasa A, Messina D, Nicoletti G, Novellino F, Lanza P, Condino F, Arabia G, Salsone M, Quattrone A. Cerebellar atrophy in essential tremor using an automated segmentation method. Am J Neuroradiol, 2009; 30: 1240-1243

Chandran V, Pal PK, Reddy JY, Thennarasu K, Yadav R, Shivashankar N. Non-motor features in essential tremor. Acta Neurol Scand, 2011; 20: 1-6

Chouinard S, Louis ED, Fahn S. Agreement among movement disorders specialist on the clinical diagnosis of essential tremor. Mov Disord, 1997; 12: 973-976

Colebatch JG, Findley LJ, Frackowiak RS, Marsden CD, Brooks DJ. Preliminary report: activation of the cerebellum in essential tremor. Lancet, 1990; 27: 1028-30

Critchley E. Clinical manifestations of essential tremor. J Neurol Neurosurg Psychiatry, 1972; 35: 365 - 372

Deuschl G, Elble RJ. The pathophysiology of essential tremor. [Review]. Neurology, 2000; 54; $11: 14$ - 20

Deuschl G, Elble R. Essential tremor--neurodegenerative or nondegenerative disease towards a working definition of ET. Mov Disord, 2009; 30: 2033-2041

Dupuis MJ, Delwaide PJ, Boucquey D, Gonsette RE. Homolateral disappearance of essential tremor after cerebellar stroke. Mov Disord, 1989; 4: 183-187

Fahn SE, Tolosa E, Marin C. Clinical rating scale for tremor. In: Jankovic J, Tolosa E, editors. Parkinson's Disease and Movement Disorders. 2nd ed. Baltimore, MA: Williams and Wilkins, 225 - 234; 1988 
Farkas Z, Szirmai I, Kamondi A. Impaired rhythm generation in essential tremor. Mov Disord, 2006; $21: 1196$ $-1199$

Fuchs AF, Robinson FR, Straube A. Role of the caudal fastigial nucleus in saccade generation. I. Neuronal discharge pattern. J Neurophysiol, 1993; 70: 1723-1740

Gitchel GT, Wetzel PA and Baron MS. Slowed saccades and increased square wave jerks in essential tremor. Tremor Other Hyperkinet Mov (NY), 2013; 3

Halliday GM, Macdonald V, Henderson JM. A comparison of degeneration in motor thalamus and cortex between progressive supranuclear palsy and Parkinson's disease. Brain, 2005; 128: 2272-2280

Helmchen C, Magenow A, Miesner J, Sprenger A, Rambold H, Wenzelburger R, Heide W, Deuschl G. Eye movement abnormalities in essentials tremor may indicate cerebellar dysfunction. Brain, 2003; 126: $1319-1332$

Higginson CI, Wheelock VL, Levine D, King DS, Pappas CT, Sigvardt KA. Cognitive deficits in essential tremor consistent with frontosubcortical dysfunction. J Clin Exp Neuropsychol, 2008: 1 - 6

Hubble JP, Busenbark KL, Pahwa R, Lyons K, Koller WC. Clinical expression of essential tremor: effects of gender and age. Mov Disord, 1997; 12: 969 - 972

Kapoula Z, Robinson DA, Optican LM. Visually induced cross-axis postsaccadic eye drift. J Neurophysiol, 1993; 69: 1031-1043

Kennard C, Lueck CJ. Oculomotor abnormalities in diseases of the basal ganglia. Rev Neurol (Paris), 1989;

145: $587-595$

Kim JS, Song IU, Shim YS, Park JW, Yoo JY, Kim YI, Lee KS. Impact of tremor severity on cognition in elderly patients with essential tremor. Neurocase, 2010; 16: 50-8

Klebe S, Stolze H, Grensing K, Volkmann J, Wenzelburger R, Deuschl G. Influence of alcohol on gait in patients with essential tremor. Neurology, 2005; 65: 96 - 101

Köster B, Deuschl G, Lauk M, Timmer J, Guschlbauer B, Lücking CH. Essential tremor and cerebellar dysfunction: abnormal ballistic movements. J Neurol Neurosurg Psychiatry, 2002; 73: 400-405

Lacritz LH, Dewey R Jr, Giller C, Cullum. CM. Cognitive functioning in individuals with "benign" essential tremor. J Int Neuropsychol Soc, 2002; 8: 125-129

Leigh RJ, Kennard C. Using saccades as a research tool in the clinical neuroscience. Brain, 2004; 127: 460 - 477

Leigh RJ, Zee DS. The Neurology of Eye Movements, 4th ed., New York: Oxford University Press; 2006

Lombardi WJ, Woolston DJ, Roberts JW, Gross, RE. Cognitive deficits in patients with essential tremor. Neurology, 2001; 57: $785-790$

Louis ED, Shungu DC, Mao X, Chan S, Jurewicz EC. Cerebellar metabolic symmetry in essential tremor studied with $1 \mathrm{H}$ magnetic resonance spectroscopic imaging: implications for disease pathology. Mov Disord, 2004; 19: 672 - 677

Louis ED, Vonsattel JP. The emerging neuropathology of essential tremor. Mov Disord, 2007; 23 : 174 - 182

Moschner C, Perlman S, Baloh RW. Comparison of oculomotor findings in the progressive ataxia syndromes. Brain, 1994; 117: 15 - 25

Pagan FL, Butman JA, Dambrosia JM, Hallett M. Evaluation of essential tremor with multi-voxel magnetic resonance spectroscopy. Neurology, 2003; 60: 1344-1347

Passamonti L, Novellino F, Cerasa A, Chiriaco C, Rocca F, Matina MS, Fera F, Quattrone A. Altered corticalcerebellar circuits during verbal working memory in essential tremor. Brain, 2011; 134: 2274-2286

Pratt J, Bekkering H, Leung M. Estimating the components of the gap effect. Exp Brain Res, 2000; 130: 258 263

Rashbass C. The relationship between saccadic and smooth tracking eye movements. Journal of Physiology, 
1961; 159: $326-338$

Robinson FR, Straube A, Fuchs AF. Role of the caudal fastigial nucleus in saccade generation. II. Effects of muscimol inactivation. J Neurophysiol, 1993; 70: 1741-1758

Sahin HA, Terzi M, Uçak S, Yapici O, Basoglu T, Onar M. Frontal functions in young patients with essential tremor: a case comparison study. J Neuropsychiatry Clin Neurosci, 2006; 18: 64 - 72

Sato H, Noda H. Saccadic dysmetria induced by transient functional decortication of the cerebellar vermis [corrected]. Exp Brain Res, 1992; 88: 455 - 458

Schiller PH, Sandell JH, Maunsell JH. The effect of frontal eye field and superior colliculus lesions on saccadic latencies in the rhesus monkey. J Neurophysiol, 1987; 57(4): 1033 - 1049

Shaikh AG, Miura K, Optican LM, Ramat S, Tripp RM, Zee DS. Hypothetical membrane mechanisms in essential tremor. J Transl Med, 2008; 6: 68

Singer C, Sanchez-Ramos J, Weiner WJ. Gait abnormality in essential tremor. Mov Disord, 1994; 9: 193 - 196

Stolze H, Petersen G, Raethjen J, Wenzelburger R, Deuschl G. The gait disorder of advanced essential tremor. Brain, 2001; 124: 2278 - 2286

Takagi M, Zee DS, Tamargo RJ. Effects of lesions of the oculomotor vermis on eye movements in primate: saccades. J Neurophysiol, 1998; 80: 1911 - 1931

Trillenberg P, Führer J, Sprenger A, Hagenow A, Kömpf D, Wenzelburger R, Deuschl G, Heide W, Helmchen C. Eye-hand coordination in essential tremor. Mov Disord, 2006; 21(3): 373 - 379

Troster AI, Woods SP, Fields JA, Lyonsc KE, Pahwad R, Higginsone CI, WC Koller. Neuropsychological deficit in essential tremor: an expression of cerebello - thalamo-cortical pathophysiology? Eur J Neurol, 2002; 9: $143-151$

Wessel K, Moschner C, Wandinger KP, Kömpf D, Heide W. Oculomotor testing in the differential diagnosis of degenerative ataxic disorders. Arch Neurol, 1998; 55: 949 - 956

Wills AJ, Jenkins IH, Thompson PD, Findley LJ, Brooks DJ. Red nuclear and cerebellar but no olivary activation associated with essential tremor: a positron emission tomographic study. Ann Neurol, 1994; 36: $636-642$

\section{Corresponding author:}

\section{Magdalena Wójcik-Pędziwiatr, MD, PhD}

The Department of Neurology

The John Paul II Hospital in Krakow

80 Prądnicka str., 31-202 Krakow, Poland

Phone.: 126142732; fax: 126142729

E-mail: m.pedziwiatr@szpitaljp2.krakow.pl 